\title{
Revised Shear Strength Model for Soil-Infilled Rock Joints Considering Over-Consolidation Effect
}

\author{
B. Indraratna University of Wollongong, Australia \\ D.A.F. Oliveira University of Wollongong, Australia
}

M. Jayanathan SRK Consulting (Pty) Ltd, Australia

\begin{abstract}
An infilled rock joint is likely to be the weakest plane in a rock mass. The most pronounced effect of the presence of infill material is to reduce the friction of the discontinuity boundaries (i.e. rock to rock contact of the joint walls). The thicker the infill the smaller the shear strength of the rock joint and, once the infill reaches a critical thickness, the infill material governs the overall shear strength and joint walls (rock) play no significant role. However, some infilled joints may gain strength over time due to consolidation mechanisms, but may be weakened upon subsequent joint movements. Several models have been proposed to predict the peak shear strength of infilled joints under both constant normal load (CNL) and constant normal stiffness (CNS) conditions, taking into account the ratio of infill thickness $(t)$ to the height of the joint wall asperity (a), i.e. t/a ratio. CNS models provide a much better accuracy of the infilled joint behaviour in the field but none of these models have focused on the over-consolidation effect of the infilling material. This paper presents a critical review on the existing models and a series of laboratory investigations carried out on idealised saw-toothed rock joints at the University of Wollongong in order to verify the effect of overconsolidation. The tests show how the over-consolidation ratio (OCR) influences the shear strength. The critical thickness, i.e., $t / a_{\text {crit }}$, decreases with increasing OCR. A revised model for predicting the peak shear strength of rough infilled joints considering the effect of OCR is presented on the basis of the laboratory tests performed.
\end{abstract}

\section{Introduction}

One of the most challenging tasks when dealing with design in a rock mass is to properly estimate its engineering properties. The main reason for this difficulty is that the rock mass is usually made up of an interlocking matrix of discrete blocks which can present different degrees of weathering and contact surfaces, varying from clean and fresh to clay covered and slickensided.

Although a considerable amount of studies has been published on the behaviour of rock joints, the great majority are on unfilled/clean joints. Owing to this lack of research, it has been common practice to assume that the shear strength of an infilled joint is that of the infill material alone. This assumption can often lead to either low cost-effectiveness or unsafe conditions. Several parameters may influence the shear strength of filled joints among which scale effects, pore pressure drainage and consolidation ratio still need to be better understood.

The most pronounced effect of the presence of a soft infill (such as clay) material to reduction of the friction of the discontinuity boundaries (i.e. rock to rock contact of the joint walls), but the shear strength will also be influenced by the nature of the infill material itself and the characteristics of the wall-filling interfaces.

Rock joints that are filled with fine materials are likely to be the weakest elements in a rock mass and can have a dominant influence on its shear behaviour due to the low frictional properties of the infill (Ladanyi and Archambault, 1977; de Toledo and de Freitas, 1993). Some infilled joints gain strength over time due to recrystallisation, bonding and consolidation. However, these joints may be weakened again upon subsequent joint movement (Indraratna and Jayanathan, 2005).

It is probable that almost all filled or unfilled discontinuities will be in an over-consolidated or pre-loaded state when exposed at the surface. Barton (1974) reported that many hydrothermally altered infills and inter- 
bedded clay infills are in an over-consolidated state. The only infilled joints that are likely to be normally consolidated are those resulting from surface weathering processes. If the infilled joints remain in a nondisplaced condition, the difference in shear strength between the normally and over-consolidated states may be considerable (Barton, 1974). Also, the degree of over-consolidation that many clay infilled joints are subjected to may exceed the over-consolidation ratios (OCRs) of the natural deposits typically encountered in practice. Therefore, it is expected that the stress history will have a significant influence on the peak shear strength of clay-infilled rough joints.

To investigate the over-consolidation effect, a detailed laboratory testing program on artificial overconsolidated joints with natural silty clay infill under undrained triaxial conditions was carried out. The laboratory tests were conducted on saw-toothed model rock joints with varying infill thickness.

\section{Existing models to predict the shear strength of infilled rock joints}

Several models have been proposed to predict the peak shear strength of infilled joints under both constant normal load (CNL) and constant normal stiffness (CNS) conditions, taking into account the ratio of infill thickness $(t)$ to the height of the joint wall asperity (a), i.e. t/a ratio (Ladanyi and Archambault, 1977; Papaliangas et al., 1990; de Toledo and de Freitas, 1993; Phien-Wej et al., 1990; Indraratna et al., 1999, 2005, 2008). See Figure 5 for graphical representation of $t$ and $a$.

The existing models can be categorised into two major groups based on: (a) shear strength drop and (b) cumulative shear strength of rock interface and infill components. Some of these models are herein presented.

\subsection{Models based on shear strength drop}

Phien-Wej et al. (1990) presented an empirical equation based on laboratory results for the determination of infilled joint strength. The authors stated that for low asperity angles the shear strength envelope is linear and becomes bi-linear at higher asperity angles. The joint behaviour was similar to the infill alone when the $t / a$ ratio reached 2. The shear displacement to attain the peak strength was greater for higher infill thickness. Based on these findings, they proposed the following expression:

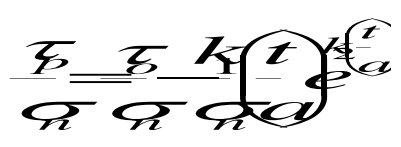

where $\tau_{\mathrm{p}}=$ peak shear strength of the infilled joint $(\mathrm{kPa}), \tau_{\mathrm{o}}=$ peak shear strength of the clean joint at same normal stress $(\mathrm{kPa}), \sigma_{\mathrm{n}}=$ normal stress $(\mathrm{kPa})$ under $\mathrm{CNL}$ condition and $\mathrm{k}_{1}$ and $\mathrm{k}_{2}=$ constants that vary with surface roughness and applied normal stress.

The second term on the right hand side of the equation is a drop in peak shear strength, i.e. the strength of the clean joint is reduced due to the presence of infill. This drop does not clearly state the parameters that may affect the shear strength such as dilation and type of infill.

Indraratna et al. (1999) based on a series of experiments under CNS condition suggested an approach similar to Phien-Wej et al. (1990) describing the peak shear strength of infilled joints in terms of a drop due to the presence of the infill. The authors defined the concept of normalised shear drop (NSD) as the reduction in peak shear stress with respect to peak shear stress for clean joints divided by the initial normal stress $\left(\Delta \tau_{\mathrm{p}} / \sigma_{\mathrm{no}}\right)$. The NSD is plotted against $t / a$ and the resulting curve can be described by a hyperbolic relationship as following:

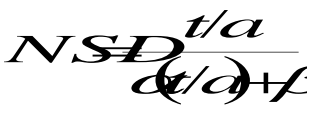

where $\alpha$ and $\beta$ are empirical constants depending on $\sigma_{\mathrm{no}}$ and surface roughness. 
The peak shear strength is then expressed:

$$
\text { (3) }
$$

where $\left(\tau_{\mathrm{p}}\right)_{\text {filled }}$ is the peak shear strength of infilled joints and $\left(\tau_{\mathrm{p}}\right)_{\text {unfilled }}$ is the peak shear strength of clean joints.

Indraratna et al. (2005) stated that, although convenient for predicting the shear strength, the major disadvantage of the previous model was the need for evaluating in advance the hyperbolic constants for various $t / a$ ratios and asperity profiles. Moreover, similarly to Phien-Wej et al. (1990) it does not clearly show the governing parameters. In addition the empirical constants were often found to be sensitive to the type of infill material and not always accurate, e.g. for graphite infill.

\subsection{Models based on cumulative shear strength of rock interface and infill components}

Ladanyi and Archambault (1977) proposed a model based on two domains to predict the shear behaviour of clay filled joints (cohesive). In the first domain the irregularities remain intact during shear and in the other breakage of irregularities takes place.

For no breakage of irregularities, the shear strength was proposed as:

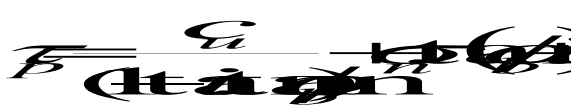

where $\sigma_{n}$ is the normal stress under CNL conditions, $i$ is the peak dilation angle and $\tan (i)=m \cdot \tan \left(i_{o}\right), i_{o}$ is the initial asperity angle, $c_{u}$ is the undrained shear strength parameter of the clay infill, $\phi_{b}$ is the basic friction angle of the rock interface. The parameter $m$ is a reduction factor, which varies between 0 and 1 , expressed by:

$$
\begin{aligned}
& m=\left[1-\frac{2}{3}\left(\frac{t}{a}\right)\right]^{2} \quad \text { for } \mathrm{t} / \mathrm{a} \leq 1.5 \\
& m=0 \quad \text { for } \mathrm{t} / \mathrm{a}>1.5
\end{aligned}
$$

where $t / a$ is the thickness of infill to asperity height ratio.

For breakage of irregularities during shear, the proposed relationships were:

$$
\mathrm{S}=\mathrm{m} \cdot(\mathrm{R}-\mathrm{C})+\mathrm{C}
$$

where $S$ is the shear strength of the infilled joint, $R$ is the shear strength of the clean joint given by $R=\sigma_{n} \tan \left(\phi_{b}+i\right), C$ the shear strength of the infill given by $C=c_{u}+\sigma_{n} \cdot \tan \left(\phi_{u}\right)$ and $\phi_{u}$ the undrained friction angle of the infill material. The peak dilation angle $i$ for the clean joint is given by:

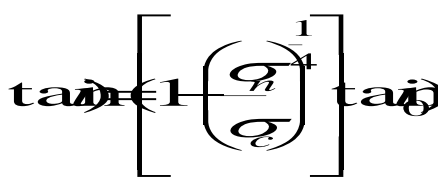

where $\sigma_{c}$ is the compressive strength of the intact rock.

It is interesting to note that for the domain of no breakage the factor $m$ is used to reduce the overall peak dilation angle of the joint due to presence of the infill, whereas for the second domain it is used to reduce the decrease in shear strength of the clean joint caused by infill. In the latter the peak dilation considered is that of the clean joint. Ladanyi and Archambault (1977) found that the second domain of their model was only valid for the following limits: $30^{\circ} \leq i_{o} \geq 45^{\circ}$ and $0.1<\left(\sigma_{n} / \sigma_{c}\right) \leq 0.5$.

Papaliangas et al. (1990), incorporating the approach suggested by Ladanyi and Archambault (1977), proposed an empirical model for predicting the peak shear strength of infilled joints. They stated that the shear strength falls in between two limits, $\tau_{\max }$ which is the maximum shear strength of the unfilled joint and $\tau_{\min }$ the minimum shear strength for a critical infill thickness. These limits vary with thickness $(t)$, type of 
infill, roughness of the rock surface and normal stress. The authors suggested that for rough, undulating and steep joints it is reasonable to assume $\tau_{\min }$ equal to the shear strength of the infill, but for planar or slightly undulating smooth joints, $\tau_{\min }$ will be equal to the shear strength of the interface, if lower than the soil infill $\left(\phi_{b}<\phi_{s o i l}\right)$. Based on these considerations, they expressed the peak shear strength as a percentage of stress ratios, as follow:

\section{Athithathi)}

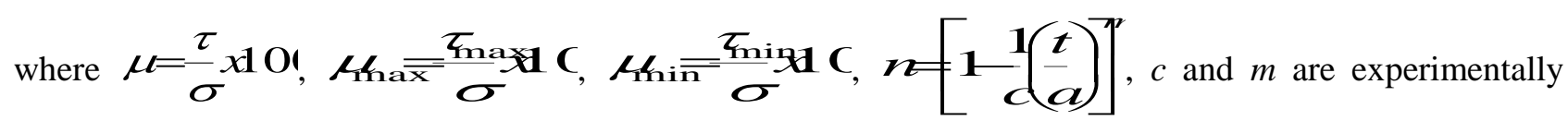
derived constants. The constant $\mathrm{c}$ is defined as the ratio $t / a$ at which the minimum shear strength is attained which is the same as $t / a_{\text {crit }}$ mentioned earlier.

The previous model introduced the concept of percentage of strength ratios for the two basic components of the shearing mechanism, the rock interface described by $\mu_{\max }$ and the infill material by $\mu_{\min }$. The major disadvantage of this model is that it requires the evaluation of the constant $m$ for various $t / a$ ratios in advance and it does not consider some of the governing parameters such as $\phi_{\mathrm{b}}$, soil friction angle $\phi_{\text {soil }}$ and $i$.

Indraratna et al. (2005) verified that the normalised peak shear strength of an infilled rock joint falls within a narrow bandwidth. In order to account different types of infill, based on this finding, they proposed a new model, describing the peak shear strength of infilled rock joints in terms of fractions of the shear strength of the rock interface and the soil infill. A normalised shear strength $\left(\tau_{p} / \sigma_{n}\right)$ semi-empirical model was proposed, describing the peak shear strength of infilled joints by two algebraic functions $A$ and $B$ with varying $t / a$ ratios for constant normal stiffness conditions (CNS). Figure 1 shows the proposed model. The relationship proposed by Patton (1966) was used to describe the role of the rock surface which influence (ratio) is controlled by a power function. The influence of the soil strength is controlled by a hyperbolic power function.

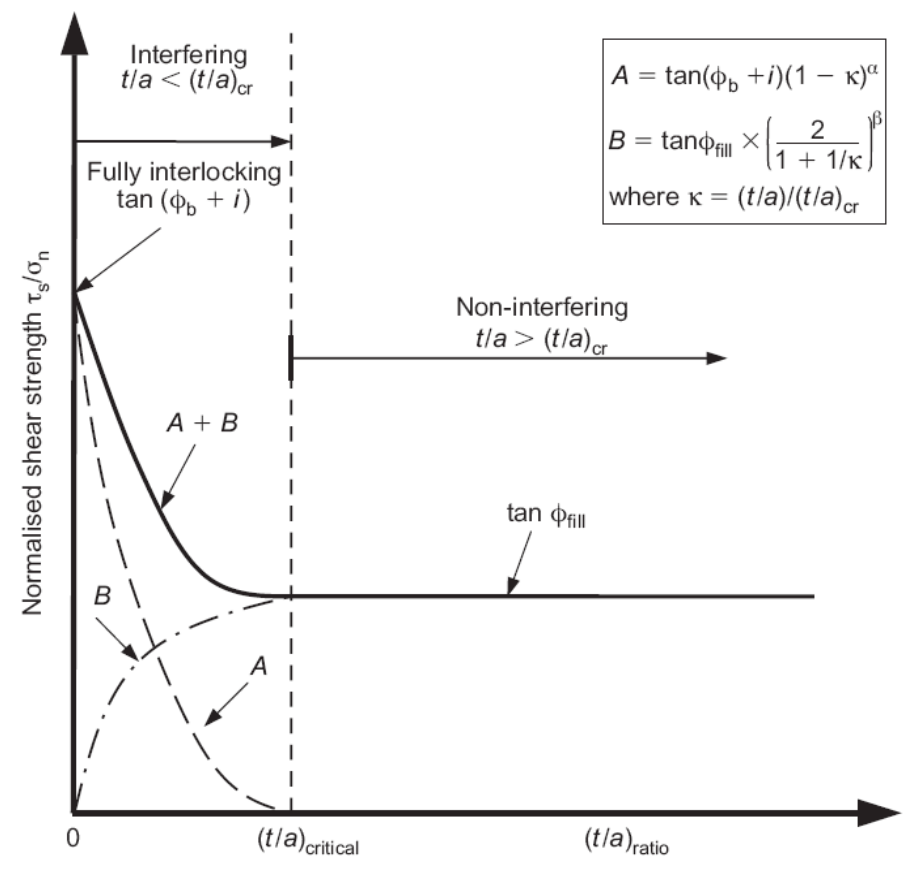

Figure 1 Conceptual normalised shear strength model for infilled joints under CNS conditions (after Indraratna et al., 2005)

The functions $A$ and $B$ are expressed in terms of properties of the rock joint ( $\phi_{b}$ and $i_{o}$ ) and of the infill material ( $\left.\phi_{\text {fill }}^{\prime}\right)$ respectively. They are fitted to laboratory data by means of the two empirical coefficients $\alpha$ and $\beta$. For $t / a$ ratio greater then the critical value $\left(t / a_{c r i t}\right)$ the function $B$ vanishes and the shear behaviour is 
controlled by $\tan \left(\phi_{\text {fill }}^{\prime}\right)$ alone, defining two main domains: an interfering zone and a non-interfering zone as proposed by de Toledo and de Freitas (1993).

This model explicitly shows some of the governing parameters. Although conveniently predicting the shear strength of infilled joints with some degree of accuracy, it requires extension to incorporate the degree of over-consolidation of the infill thus providing a more comprehensive shear strength model.

\section{Laboratory procedure}

For reasons of simplicity and reproducibility, idealised model rock joints with regular saw-toothed surfaces were cast with a mean dip angle of $60^{\circ}$. Preliminary triaxial testing of unfilled idealised joints indicated that for the applied stress conditions employed in this study, dip angles of less than $60^{\circ}$ were generally not conducive to the initiation of sliding along the joint plane. The asperity height (a) and the initial asperity angle $\left(i_{0}\right)$ of the saw-toothed joint surfaces were $2 \mathrm{~mm}$ and $18^{\circ}$, respectively.

Gypsum plaster was used as casting material because it provides favourable similitude properties for most sedimentary rock types. The long-term strength of this plaster is independent of time once the chemical hydration is completed. The plaster was mixed with water in a ratio of $5: 3$ by weight and poured into the mould with the application of a mild vibration to release any entrapped air. After being left for at least one hour to ensure adequate hardening, the specimen was removed from the mould and cured at an ovencontrolled temperature of $45^{\circ} \mathrm{C}$ for two weeks. Cured cylindrical specimens with a height to diameter ratio of 2 gave consistent unconfined compressive strengths $\left(\sigma_{c}\right)$ of 11-13 MPa. The mechanical properties of this low porosity model material have been reported by Indraratna (1990). Figures 2 and 3 show the mould used and the specimen.

The high-pressure two-phase triaxial apparatus at the University of Wollongong (Indraratna et al., 1999) was modified for this study. A variable constant-strain mechanical driving system was installed to apply a constant axial strain rate to the infilled joint under a given confining pressure. The loading capacity of the driving system was $150 \mathrm{kN}$ and the travel length $120 \mathrm{~mm}$. A load cell and a displacement transducer were used to measure the axial load and vertical displacement respectively. A system of two thin spring-steel cantilever arms was mounted on the base of the triaxial cell for measuring horizontal displacement. Two strain gauges were attached to each arm and connected to a Wheatstone bridge. The final dilation is then calculated by the composition of vertical and horizontal displacement.

The clay-infilled jointed specimen wrapped in a latex membrane was assembled inside the modified triaxial cell. The specimens were consolidated at an elevated confining pressure. At the end of consolidation, the confining pressure was reduced to a predetermined value to achieve a specified over-consolidation ratio of the infill. Tests under effective confining pressure of 200, 300 and $500 \mathrm{kPa}$ were carried out on infilled joints having infill thickness to asperity height $t / a$ ratios of between 0.5 and 5.0. Shear behaviour was investigated for infill OCRs of 1,2, 4, and 8. Further details of the test procedure can be found in Indraratna and Jayanathan (2005) and Indraratna et al. (2008).

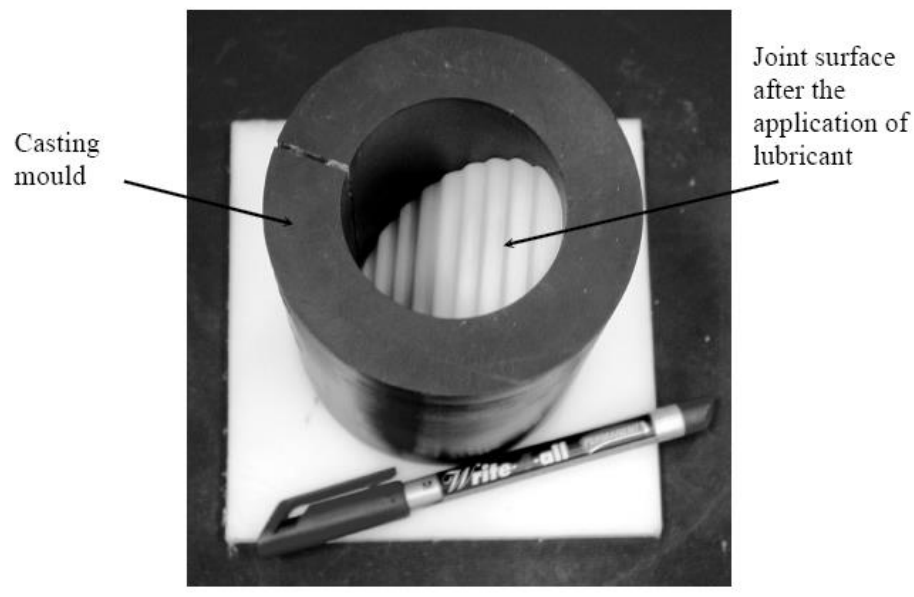

Figure 2 Mould with joint profile for casting idealised rock joints (after Indraratna et al., 2008) 


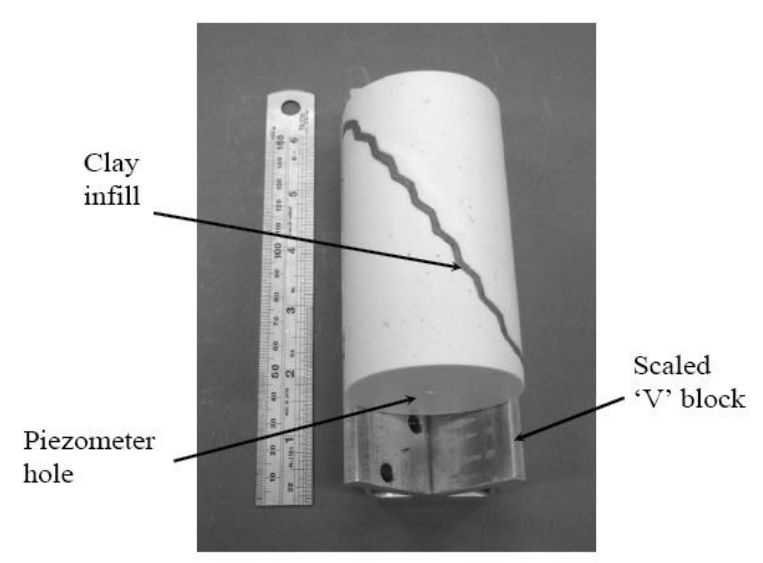

Figure 3 Infilled idealised joint for triaxial testing (after Indraratna et al., 2008)

\section{Revised model incorporating over-consolidation effect}

It is well know that the stress history plays an important role in the shear strength of soils. Clayey soils that have been subjected to a preloading (pre-consolidation) stress in excess of its existing overburden are overconsolidated. The ratio between its maximum past stress and its present in situ stress is the overconsolidation ratio (OCR). According to Barton (1974), it is probable that almost all discontinuities will be in an over-consolidated state when exposed at the surface.

The laboratory investigation performed showed that for small thickness, where a pronounced two peak behaviour is observed corresponding to yielding of infill (first portion of the curve) and rock-to-rock contact, the effect of OCR is noted mainly by the increase of the first peak. Beyond this point, the stress-strain curves for all OCR values are almost parallel up to the deviator stress peak, which is associated with the rock-torock contact. The total increase in stress after the first peak remains almost constant at approximately $700 \mathrm{kPa}$, independently of OCR. It is also verified that the first peak is attained at lower axial strains. This indicates that in order to incorporate the effect of OCR only the infill term described by function $B$ in the conceptual normalised shear model needs to be modified. Figure 4 shows a typical test result.

$\mathrm{t} / \mathrm{a}=0.5$

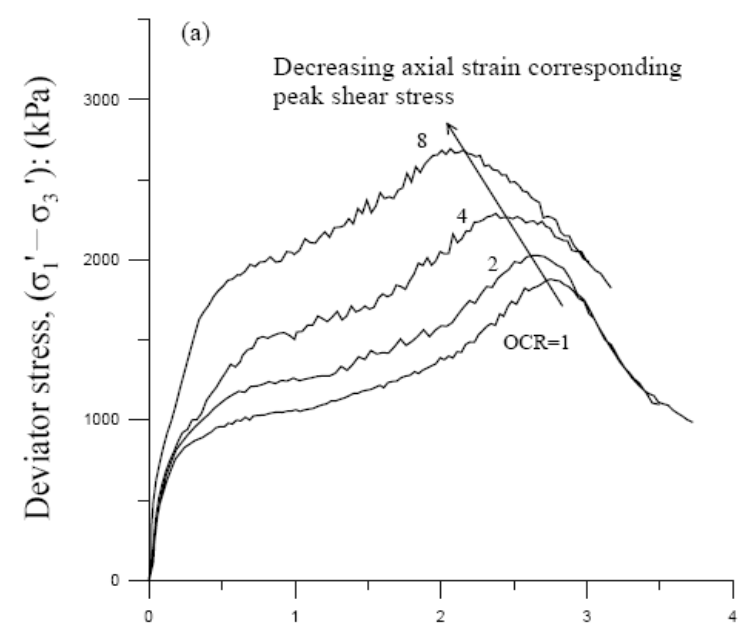

$\mathrm{t} / \mathrm{a}=3.5$

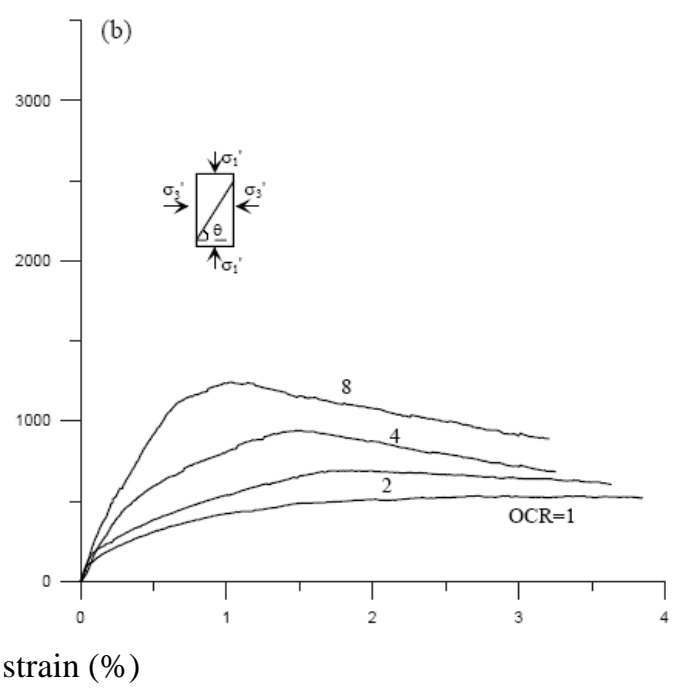

Figure 4 Shear behaviour of infilled saw-toothed joints with $t / a=0.5$ and 3.5 at $\sigma_{3}^{\prime}=500 \mathrm{kPa}$ 
Plotting the normalised peak shear strength for different OCR values, it was verified that the critical $t / a$ ratio decreases with increasing OCR (Figure 5).

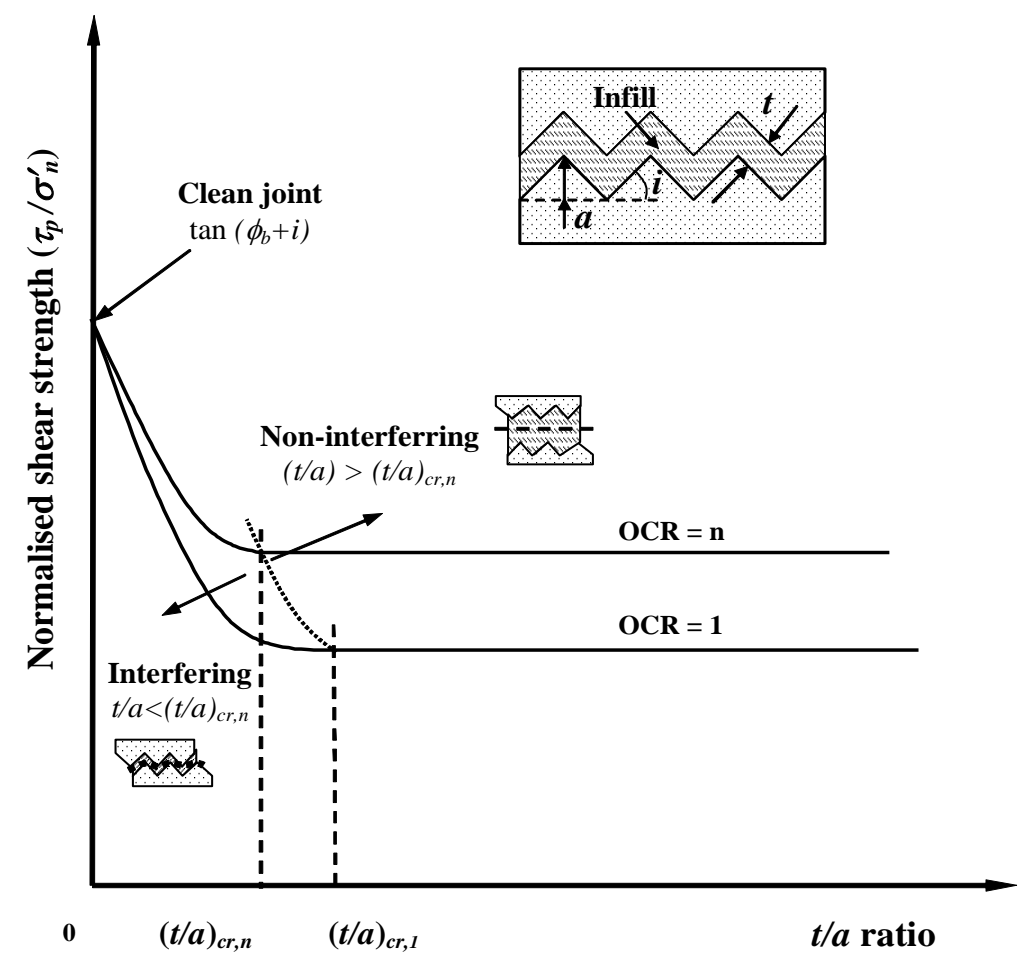

Figure 5 Effect of OCR on normalised shear strength model (after Indraratna et al., 2008)

Based on these findings, it is hypothesised that the strength of the over-consolidated infill can be expressed by the normally consolidated material and the OCR. In order to better represent the effect of the OCR the " $\mathrm{x}$ " axis of the conceptual normalised peak shear strength model was also normalised by:

$$
k_{\text {oc. } n}=\frac{(t / a)_{o c, n}}{(t / a)_{c r, n}}
$$

where $(t / a)_{c r, n}$ is the critical $t / a$ ratio of an infilled joint with an OCR of $n$ and $(t / a)_{o c, n}$ is given value of $t / a$ for an infilled joint with OCR of $n$.

Using the method proposed by Ladd and Foott (1974) to describe the shear strength of over-consolidated soil as a function of the shear strength of normally consolidated soils and OCR, the following expression can be derived for the infill term:

$$
\left(\tau_{p} / \sigma_{n}^{\prime}\right)_{o c, n}=\tan \varphi_{f i l l}^{\prime} \times O C R^{\alpha}
$$

Therefore, for $t / a<t / a_{\text {crit }}$ or $k_{\mathrm{oc}, n}<1$, i.e. the interfering zone, the conceptual normalised peak shear strength model proposed by Indraratna et al. (2005) can be rewritten to incorporate the over-consolidation effect as:

$$
\left(\frac{\tau_{p}}{\sigma_{n}^{\prime}}\right)_{o c, n}=A_{n}+B_{n}=\tan \left(\phi_{b}+i\right) \times\left(1-k_{o c, n}\right)^{a_{n}}+\tan \varphi_{f i l l}^{\prime} \times O C R^{\alpha} \times\left(\frac{2}{1+1 / k_{o c, n}}\right)^{b_{n}}
$$

where $\phi_{\text {fill }}^{\prime}$ is the effective friction angle of normally consolidated infill, and $a_{n}$ and $b_{n}$ are empirical constants defining the geometric loci of the functions $A_{n}$ and $B_{n}$, respectively. 
For $\mathrm{k}_{\mathrm{oc}, \mathrm{n}}>1$ (non-interfering zone) the normalised shear strength is controlled solely by the function $\mathrm{B}_{\mathrm{n}}$. Figure 6 shows the revised conceptual model and Figure 7 presents the calibration of the model with experimental data.

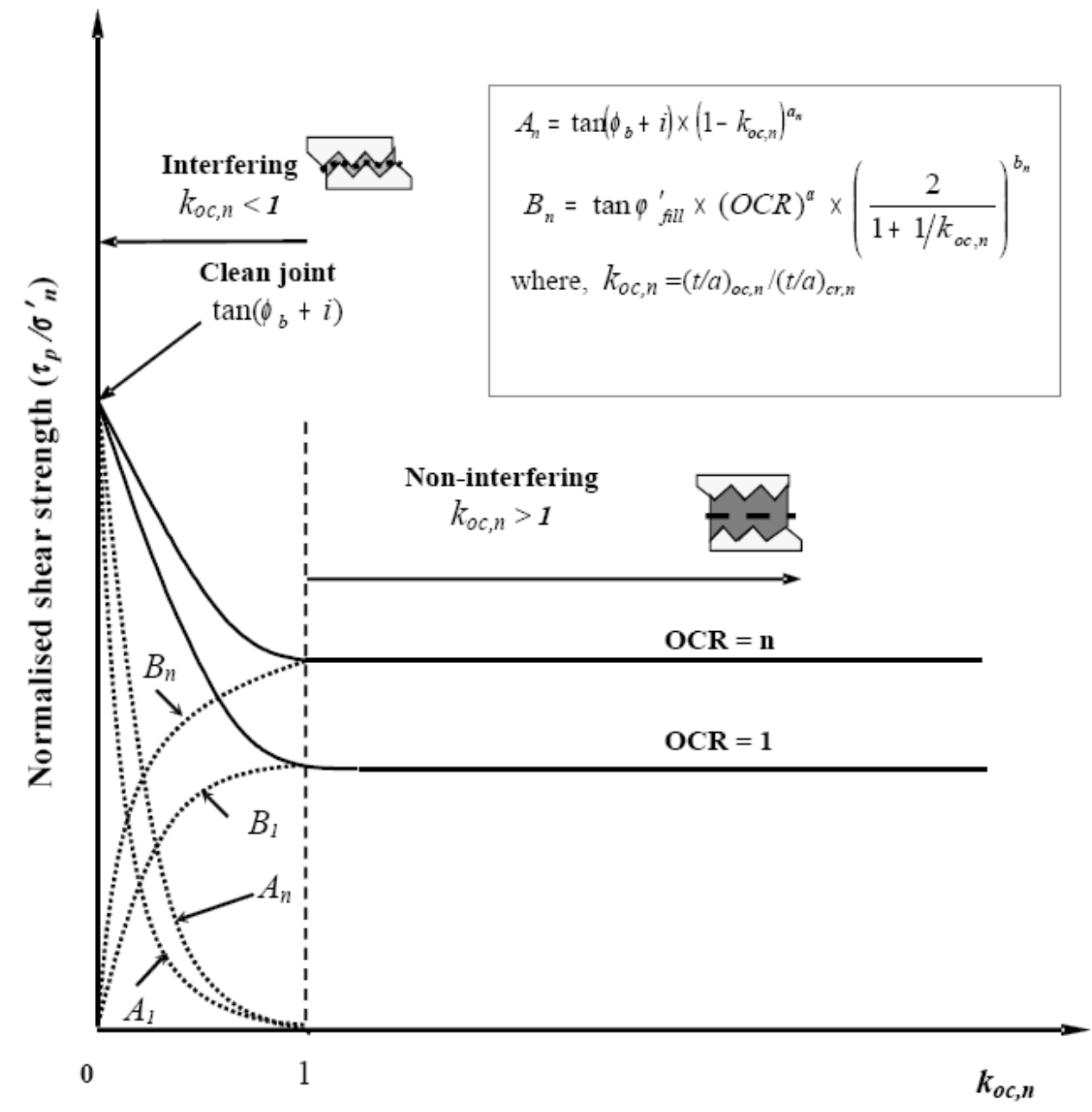

Figure 6 Revised conceptual normalised peak shear strength model (after Indraratna et al., 2008)

\section{Conclusions}

The normalised conceptual model clearly shows that the shear strength of an infilled joint can be described as the effect of its two components combined, i.e. infill and rock surface. With this concept, the effect of over-consolidation could be readily considered in the infill shear strength term.

The effect of OCR is noted mainly by the increase of the first peak and the $t / a_{\text {crit }}$ value decreases in a predictable manner that can be quantified mathematically in terms of OCR. For the infill term, described by function $B_{n}$, the governing parameters are the friction angle, which controls the first peak (soil failure) and the OCR. For the rock term, $A_{n}$, the main parameters are the basic friction angle of the rock surface and the joint profile, which affects the overall dilation.

The current proposed model has been validated only for saw-toothed joints with clay infills. Further testing of other types of infills and joint geometries at different confining pressures will be required to establish a more comprehensive database of the relevant parameters $\left(\alpha, a_{n}\right.$, and $\left.b_{n}\right)$ to represent a wider array of jointinfill combinations. 

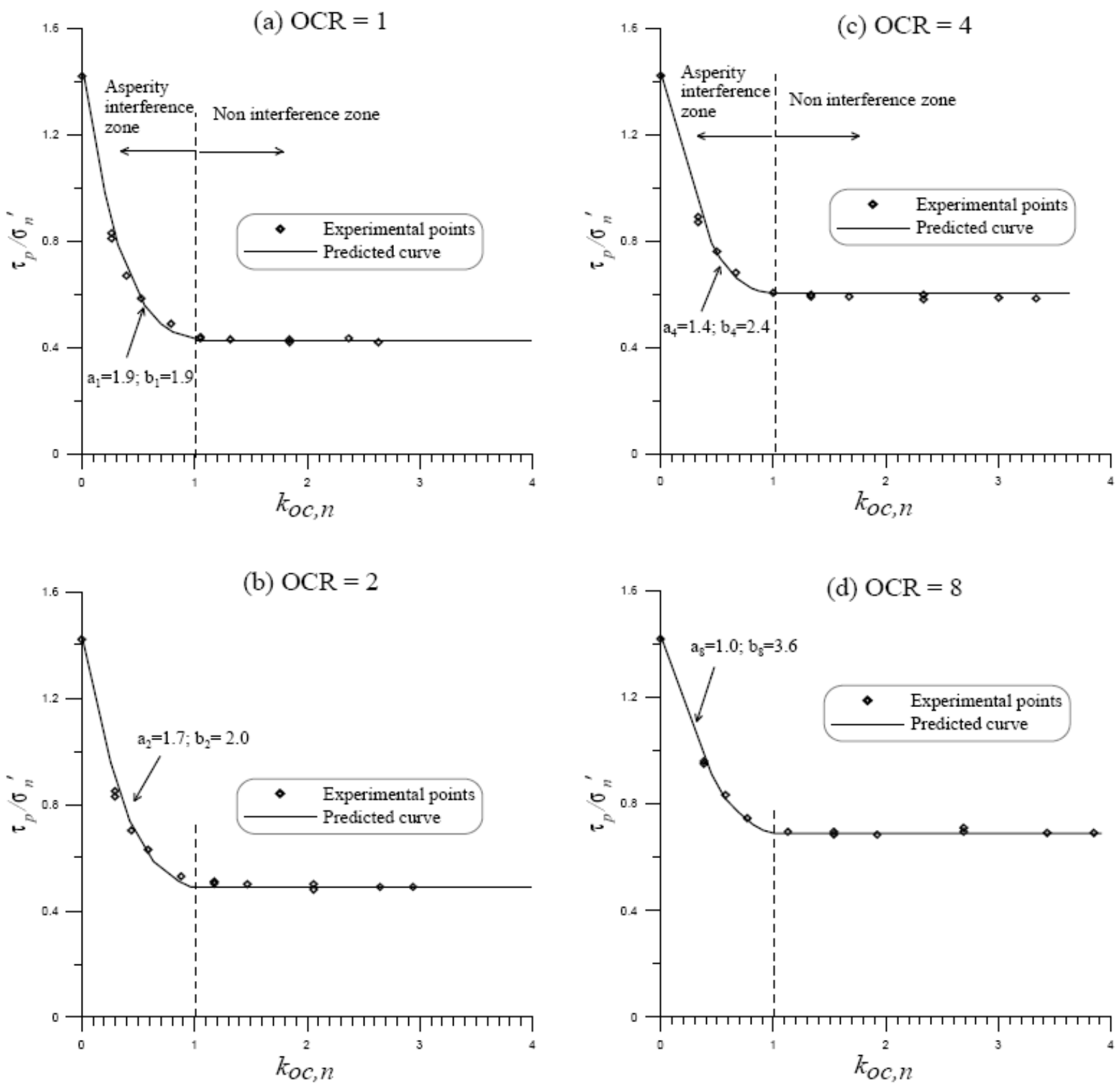

Figure 7 Verification with experimental data of revised conceptual model for over-consolidated infilled joints (after Indraratna et al., 2008)

\section{Acknowledgements}

The authors wish to acknowledge the contributions of the technical staff at the University of Wollongong, during the modification of the experimental set-up and the testing program. The assistance of Professor E.T. (Ted) Brown during the research program is also appreciated. The authors also would like to acknowledge the comments of the reviewers and to mention that the suggestion of combining numerical modelling is part of the ongoing research.

\section{References}

Barton, N. (1974) Review of shear strength of filled discontinuities in rock. Publication No. 105. Oslo: Norwegian Geotechnical Institute, $38 \mathrm{p}$.

de Toledo, P.E.C. and de Freitas, M.H. (1993) Laboratory testing and parameters controlling the shear strength of filled rock joints. Géotechnique 43, No. 1, pp. 1-19. 
Indraratna, B. and Jayanathan, M. (2005) Measurement of pore water pressure of clay-filled rock joints during triaxial shearing. Géotechnique 55, No. 10, pp. 759-764.

Indraratna, B., Welideniya, H.S. and Brown, E.T. (2005) A shear strength model for idealised infilled joints under Constant Normal Stiffness (CNS). Géotechnique 55, No. 3, pp. 215-226.

Indraratna, B., Haque, A. and Aziz, N. (1999) Shear behaviour of idealised infilled joints under constant normal stiffness. Géotechnique 49, No. 3, pp. 331-355.

Indraratna, B. (1990) Development and applications of a synthetic material to simulate soft sedimentary rocks. Géotechnique 40, No. 2, pp. 189-200.

Indraratna, B., Jayanathan, M. and Brown, E.T. (2008) Shear strength model for over-consolidated clay-infilled idealised rock joints. Géotechnique 58, No. 1, pp. 55-65.

Ladanyi, B. and Archambault, G. (1977) Shear strength and deformability of filled indented joints. Proc. 1st Int. Symp. on Geotechnics of Structurally Complex Formations, Capri, pp. 317-326.

Ladd, C.C. and Foott, R. (1974) New design procedure for stability of soft clays. J. Geotech. Engrg., ASCE 100 , No. GT7, pp. 763-786.

Papaliangas, T., Lumsden, A.C., Hencher, S.R. and Manolopoulou, S. (1990) Shear strength of modelled filled rock joints. Proceedings Int. Conf. on Rock Joints, N.R. Barton and O. Stephansson (eds.), Balkema (Rotterdam), pp. 275-282.

Patton, F.D. (1966). Multiple modes of shear failure in rocks. Proc. 1st Congr. Int. Soc. Rock Mech., Lisbon, pp. 509-513.

Phien-Wej, N., Shrestha, U.B. and Rantucci, G. (1990) Effect of infill thickness on shear behaviour of rock joints. Rock Joints, Proceedings Int. Conf. on Rock Joints, Loen, N.R. Barton and O. Stephansson (eds.), Balkema (Rotterdam), pp. 289-294. 